\title{
Are traded forest tree seeds a potential source of nonnative pests?
}

\author{
Iva Franić, $, 1,2,3,9$ Simone Prospero, ${ }^{2}$ Martin Hartmann, ${ }^{4}$ Eric Allan, ${ }^{3}$ \\ Marie-Anne Auger-Rozenberg, ${ }^{5}$ Niklaus J. Grünwald,${ }^{6}$ Marc Kenis, ${ }^{1}$ Alain Roques, ${ }^{5}$ Salome Schneider, ${ }^{2}$ \\ Richard Sniezko, ${ }^{7}$ Wyatt Williams, ${ }^{8}$ and René Eschen $^{1}$ \\ ${ }^{1}$ CABI, Delémont, Switzerland \\ ${ }^{2}$ Swiss Federal Institute for Forest, Snow and Landscape Research WSL, Birmensdorf, Switzerland \\ ${ }^{3}$ Institute of Plant Sciences, University of Bern, Bern, Switzerland \\ ${ }^{4}$ Institute of Agricultural Sciences, ETH Zürich, Zürich, Switzerland \\ ${ }^{5}$ URZF, INRA, Orléans, France \\ ${ }^{6}$ USDA Horticultural Crops Research Unit, Corvallis, Oregon 97330, USA \\ ${ }^{7}$ Dorena Genetic Resource Center, USDA Forest Service, Cottage Grove, Oregon 97424, USA \\ ${ }^{8}$ Private Forests Division, Oregon Department of Forestry, Salem, Oregon 97310, USA
}

Citation: Franić, I., S. Prospero, M. Hartmann, E. Allan, M.-A. Auger-Rozenberg, N. J. Grünwald, M. Kenis, A. Roques, S. Schneider, R. Sniezko, W. Williams, and R. Eschen. 2019. Are traded forest tree seeds a potential source of nonnative pests? Ecological Applications 29(7):e01971. 10.1002/eap.1971

Abstract. The international seed trade is considered relatively safe from a phytosanitary point of view and is therefore less regulated than trade in other plants for planting. However, the pests carried by traded seeds are not well known. We assessed insects and fungi in 58 traded seed lots of 11 gymnosperm and angiosperm tree species from North America, Europe, and Asia. Insects were detected by X-raying and molecular methods. The fungal community was characterized using high-throughput sequencing (HTS) and by growing fungi on non-selective agar. About 30\% of the seed lots contained insect larvae. Gymnosperms contained mostly hymenopteran (Megastigmus spp.) and dipteran (Cecidomyiidae) larvae, while angiosperms contained lepidopteran (Cydia latiferreana) and coleopteran (Curculio spp.) larvae. HTS indicated the presence of fungi in all seed lots and fungi grew on non-selective agar from $96 \%$ of the seed lots. Fungal abundance and diversity were much higher than insect diversity and abundance, especially in angiosperm seeds. Almost $50 \%$ of all fungal exact sequence variants (ESVs) found in angiosperms were potential pathogens, in comparison with around $30 \%$ of potentially pathogenic ESVs found in gymnosperms. The results of this study indicate that seeds may pose a greater risk of pest introduction than previously believed or accounted for. A rapid risk assessment suggests that only a small number of species identified in this study is of phytosanitary concern. However, more research is needed to enable better risk assessment, especially to increase knowledge about the potential for transmission of fungi to seedlings and the host range and impact of identified species.

Key words: alien pests; fungal pathogens; insect pests; pathways risk assessment; pest risk assessment; phytosanitary risk; seed trade.

\section{INTRODUCTION}

Nonnative insect pests and fungal pathogens (later referred to as pests; FAO 2016) represent one of the major threats to trees and forest ecosystems worldwide (Boyd et al. 2013). These pests can cause significant ecological changes (Kenis et al. 2009, Loo 2009) and economic losses (Holmes et al. 2009, Aukema et al. 2011) by severely damaging or killing their host plants. For example, the Asian emerald ash borer (Agrilus planipennis Fairmaire) has caused a large-scale death of ash trees (Fraxinus spp.) in North America and is threatening

Manuscript received 27 March 2019; revised 4 June 2019; accepted 14 June 2019. Corresponding Editor: Paul Cross.

${ }^{9}$ E-mail: i.franic@cabi.org native ash species in Europe (Herms and McCullough 2014, Orlova-Bienkowskaja 2014). Similarly, the fungal pathogen Cryphonectria parasitica (Murrill) Barr virtually eliminated the native American chestnut (Castanea dentata (Marsh.) Borkh.) from North American forests in the early 20th century, which led to significant changes in the forest species composition (e.g., Shackleton et al. 2018).

The number of nonnative forest pests has been increasing rapidly, mainly due to the growing international trade in plants for planting (P4P; Liebhold et al. 2012, Santini et al. 2013, Eschen et al. 2014). The origin of nonnative pests in Europe reflects historical patterns of trade, with North America historically being the most important trading partner (Desprez-Loustau 2009). Imports of P4P from Asia into Europe have been 
increasing recently, for example, imports from China have increased sixfold between 2000 and 2018 and are now equal to imports from North America (Eschen et al. 2014). Almost $50 \%$ of the nonnative terrestrial arthropods in Europe are of Asian (26.7\%) or North American $(21.9 \%)$ origin (Roques 2010$)$ and nonnative pathogens in Europe follow a similar trend (35\% from North America and 19\% from Asia; Desprez-Loustau 2009). The importance of the recent shift in trade partners should not be underestimated because Eastern Asia has high plant diversity (Kreft and Jetz 2007) and exported plants might contain a high number of pests.

Some recent studies suggest that plant diversity is positively related to the diversity of associated insects (O'Brien et al. 2017, Liebhold et al. 2018), which could be due to the larger number of niches occupied by specialist herbivorous insects, which then could increase the diversity on higher trophic levels, such as of predatory insects (i.e., diversity-trophic-structure hypothesis; Hutchinson 1959). The relationship with plant diversity is much less explored for fungi. Fungal communities are normally composed of only small fractions of specialist fungi that show unclear levels of host affinity (Arnold and Lutzoni 2007, Higgins et al. 2007, Vincent et al. 2016). Therefore, a similar relationship between plant and fungal diversity could be expected. Similarly, geographic areas with higher plant diversity or more diverse plant taxa could have a higher associated insect or fungal diversity. This however does not necessarily imply a higher pest or pathogen diversity, since associated organisms may also be commensalists or mutualists (Rodriguez et al. 2009). Yet, the taxonomy of traded plant material may affect pest risk: angiosperms harbor more nonnative pests than gymnosperms (Santini et al. 2013, Eschen et al. 2015) perhaps because they are a more species-rich group. It has previously been suggested that gymnosperms and angiosperms recruit distinctive communities of associated organisms (Ishida et al. 2006, Arnold 2007, Zhou and Dai 2011), but we are unaware of studies of the differences in phytosanitary risk between angiosperms and gymnosperms (i.e., probability of pest transport).

Among the most damaging seed pests of angiosperms are larvae of weevils (Coleoptera: Curclionidae) and moths (Lepidoptera: Tortricidae), which can significantly affect crop yield (Myczko et al. 2017). However, these larvae usually leave the seeds to pupate in the ground and are, thus, less likely to be moved with seeds. In gymnosperms, the dominant group of spermatophagous insects (i.e., insects that spend the whole life cycle in seeds) are chalcid wasps of the genus Megastigmus (Hymenoptera: Chalcidoidea) (Turgeon et al. 1994). Hence, spermatophagous insects are considered to be more relevant from a phytosanitary point of view, also because they are likely to go unnoticed during phytosanitary inspections (Auger-Rozenberg and Roques 2012). The world checklist of fungi includes over 550 seed-borne taxa with most records originating from North America and Europe (Mittal et al. 1990). However, interactions of seed-borne fungi with the host seem to be more complex than the interactions between spermatophagous insects and their hosts, with only a fraction of the fungi being pathogenic (Benitez et al. 2013, Cleary et al. 2019, Liu and He 2019). Moreover, only pathogens that are transmitted to the seedling (vertical transmission) may represent a phytosanitary threat (Burgess and Wingfield 2002).

Plant health regulations and phytosanitary measures are designed to reduce the risk of introducing pests. However, regulatory measures in most countries target only known pest species, which may overlook many potential nonnative pests as most were not known to be harmful prior to their introduction, or were not even known to science (Eschen et al. 2015). Furthermore, due to the increasing volume of international trade in P4P, only a small fraction of traded goods can be inspected (Brasier 2008), often only visually, which is not sufficient to detect latent, rare, or hidden pests (Venette et al. 2002, Slippers and Wingfield 2007). In addition, different types of P4P may vary in the number of potential pests that they carry. As a result, regulations for subcategories of P4P vary significantly, with trade in living plants, with soil, roots, or leaves, being significantly more restricted than trade in seeds (Anonymous 2000). In particular, trade in seeds is rarely considered to be a major pathway of pest introduction (Kenis et al. 2007, Liebhold et al. 2012, Santini et al. 2013) and seeds are, therefore, considered to represent a relatively low phytosanitary risk. This is best illustrated by the fact that among the 233 regulated organisms associated with $\mathrm{P} 4 \mathrm{P}$ in the EU, Fusarium circinatum Nirenberg \& O'Donnell, the causal agent of pitch canker, is the only seed-borne pathogen. This means that the European Union stipulates that only pine (Pinus spp.) and Douglas-Fir (Pseudotsuga menziensii (Mirb.) Franco) seeds are subjected to specific phytosanitary requirements for import and internal movement (Vettraino et al. 2018). In other parts of the world, the phytosanitary import requirements for seeds are often stricter to specifically prevent the introduction of seed-borne diseases (e.g., Canada, Australia). The value and volume of the international trade in forest tree seeds are very difficult to assess. Since seeds are considered to be part of the P4P pathway they are not listed separately in trade statistics and certainly not at the species level.

We assessed seed-borne insects and fungi associated with commercially traded seeds of 11 tree species. In particular, we explored the differences in overall insect and pathogen infestation and diversity, as well as in infestation by potentially harmful pests, between seeds of different taxonomic groups (angiosperms and gymnosperms) and origins (Europe, Asia, and North America). We tested the following hypotheses: (1) angiosperms have higher insect and fungal diversity than gymnosperms, (2) Asian seeds contain higher insect and fungal diversity than European and North American 
seeds, because Asia is one of the most biodiverse regions of the world, and (3) Europe and North America have more similar seed-borne pest communities, in comparison with Asia, as a result of the historically more intense trade in P4P between Europe and North America.

\section{Methods}

\section{Seed origin and assessment of seed size}

Seeds and nuts (later referred to as seeds) of 11 tree species, belonging to three families within the angiosperms and gymnosperms, and native to Europe, Asia, or North America, were bought from three to eight localities from commercial seed suppliers in Europe and North America in autumn/winter 2016 (Table 1; Appendix S1: Table S1). A total of 58 seed lots (SL), of 100 seeds each, were obtained from the native continent of a tree species from locations with similar, temperate climates (i.e., Western North America, Europe, and Eastern Asia). Seeds of Asian species and of Asian origin were purchased from suppliers in Europe and North America. Hence, these seeds and their associated organisms originated from the native range of their host tree. We were able to obtain detailed information about the origin of most European and North America seeds, but could not obtain this information for the Asian seeds (Appendix S1: Table S1). From the 58 lots, five originated from a region that was slightly outside the native range of the tree species (but still from the continent or origin): two seed lots of Picea abies (L.) H. Karst. from Central France and Hungary (SL 24, SL 59), two seed lots of Pinus sylvestris L. from United Kingdom (SL 56, SL 57), and one seed lot of Acer pseudoplatanus L. from United Kingdom (SL 63; Appendix S1: Table S1).
A total of 20 seed lots each of 100 seeds (two seed lots from each of 10 of the 11 studied species) were scanned using a flatbed scanner, and cross sectional area (later referred to as seed size) was measured using ImageJ software (Schneider et al. 2012). The seeds of the North American Quercus garryana Douglas ex Hook were not measured because they were delivered late; the seeds of this species are typically ca. $3 \mathrm{~cm}$ long and $1.3 \mathrm{~cm}$ wide (Niemiec et al. 1995). The average seed size and its standard error were calculated for each seed lot.

Insect and fungal assessments were done on 53-58 seed lots (Appendix S1: Table S1), on 100 seeds per seed lot.

\section{Insect assessment}

For 56 out of 58 obtained seed lots, the seeds were X-rayed to reveal the presence of insects (Appendix S1: Table S1), as described by Roques and Skrzypczyńska (2003). Two seed lots of Fagus sylvatica L. (SL 72 and SL 73) were not assessed for insects because of late delivery. Infested seeds were dissected with a dissecting knife, and insects were collected and individually stored in collection tubes with 95-99\% ethanol. All larvae were examined using a microscope and were identified to order level. All seeds were also visually inspected for exit holes of insects.

Genomic DNA was extracted from individual insect specimens with DNeasy Blood \& Tissue Kit (Qiagen, Hilden, Germany) according to the manufacturer's instructions. A fragment of the mitochondrial gene (mtDNA) cytochrome oxidase c subunit 1 (COI) was subsequently amplified by PCR in $25 \mu \mathrm{L}$ reaction volumes containing $2 \mu \mathrm{L}$ of DNA template, $0.2 \mu \mathrm{mol} / \mathrm{L}$ of each of the primers LCO1490 and HCO2198 (Folmer

TABLE 1. Study species, taxonomy, and origins of the seed lots.

\begin{tabular}{|c|c|c|c|c|c|}
\hline Tree species & Common names & Family & Group & Origin & $\begin{array}{l}\text { No. seed } \\
\text { lots }\end{array}$ \\
\hline Acer macrophyllum Pursh & bigleaf maple, Oregon maple & Sapindaceae & Angiosperm & North America & 6 \\
\hline $\begin{array}{l}\text { Quercus garryana Douglas ex } \\
\text { Hook }\end{array}$ & $\begin{array}{l}\text { Garry oak, Oregon white oak, } \\
\text { Oregon oak }\end{array}$ & Fagaceae & Angiosperm & North America & 6 \\
\hline $\begin{array}{l}\text { Pinus ponderosa Douglas ex } \\
\text { C. Lawson }\end{array}$ & $\begin{array}{l}\text { Ponderosa pine, bull pine, } \\
\text { blackjack pine, western } \\
\text { yellow-pine }\end{array}$ & Pinaceae & Gymnosperm & North America & 8 \\
\hline $\begin{array}{l}\text { Tsuga heterophylla (Raf.) } \\
\text { Sarg. }\end{array}$ & $\begin{array}{l}\text { western hemlock, western } \\
\text { hemlock-spruce }\end{array}$ & Pinaceae & Gymnosperm & North America & 7 \\
\hline Acer pseudoplatanus L. & sycamore & Sapindaceae & Angiosperm & Europe & 3 \\
\hline Fagus sylvatica $\mathrm{L}$. & common beech & Fagaceae & Angiosperm & Europe & 6 \\
\hline Pinus sylvestris L. & Scots pine & Pinaceae & Gymnosperm & Europe & 5 \\
\hline Picea abies (L.) H. Karst. & $\begin{array}{l}\text { Norway spruce, European } \\
\text { spruce }\end{array}$ & Pinaceae & Gymnosperm & Europe & 5 \\
\hline Acer palmatum Thunb. & $\begin{array}{l}\text { palmate maple, Japanese maple, } \\
\text { smooth Japanese maple }\end{array}$ & Sapindaceae & Angiosperm & Asia & 5 \\
\hline Pinus tabuliformis Carrière & $\begin{array}{l}\text { Manchurian red pine, southern } \\
\text { Chinese pine, Chinese red pine }\end{array}$ & Pinaceae & Gymnosperm & Asia & 4 \\
\hline Larix gmelinii (Rupr.) Kuzen. & Dahurian larch & Pinaceae & Gymnosperm & Asia & 3 \\
\hline
\end{tabular}

Note: The number of seed lots of each species that were analysed is also indicated. 
et al. 1994) and $1 \times$ JumpStart REDTaq ReadyMix Reaction Mix (Sigma-Aldrich, Steinheim, Germany). PCR was performed using a Veriti 96-Well Thermal Cycler (Applied Biosystems, Foster City, California, USA) with the following settings: $2 \mathrm{~min}$ at $94^{\circ} \mathrm{C}$, five cycles of $30 \mathrm{~s}$ at $94^{\circ} \mathrm{C}, 40 \mathrm{~s}$ at $45^{\circ} \mathrm{C}$, and $1 \mathrm{~min}$ at $72^{\circ} \mathrm{C}$, 35 cycles of $30 \mathrm{~s}$ at $94^{\circ} \mathrm{C}, 50 \mathrm{~s}$ at $51^{\circ} \mathrm{C}$, and $1 \mathrm{~min}$ at $72^{\circ} \mathrm{C}$, and a final extension of $10 \mathrm{~min}$ at $72^{\circ} \mathrm{C}$. Successful amplification was confirmed by electrophoresis of the PCR products in $1.5 \%(\mathrm{w} / \mathrm{v})$ agarose at $90 \mathrm{~V}$ for $30 \mathrm{~min}$ with ethidium bromide staining. Sanger sequencing was performed using the same primers and BigDye Terminator v3.1 Cylce Sequencing Kit (Applied Biosystems). Sequences were assembled and edited with CLC DNA Workbench (Qiagen) and compared against reference sequences in the BOLDSYSTEMS (Ratnasingham and Hebert 2007) and National Centre for Biotechnology Information (NCBI) GenBank databases (Geer et al. 2010). The specimens' queries were matched to its best matching identified reference sequence for identification.

\section{Fungal assessment by plating}

Seed-borne fungal communities were determined by isolating fungal cultures from 53 out of 58 seed lots (Appendix S1: Table S1). For two seed lots of Pinus ponderosa Douglas ex Hook (SL 49, SL 50) and Tsuga heterophylla (Raf.) Sarg. (SL 51, SL 66) each and one seed lot of $F$. sylvatica (SL 73), fungal community was not assessed by plating because of late delivery. Seeds were first surface sterilized in $0.5 \%$ sodium hypochlorite $(\mathrm{NaClO})$ for $5 \mathrm{~min}$, followed by rinsing in sterile water for $2 \times 5 \mathrm{~min}$ (Gamboa et al. 2003) to eliminate environmental contamination, and were then air dried in a laminar flow cabinet. The surface sterilized seeds were then cut in half using a dissecting knife. One half of each seed was set aside and kept in a freezer for high-throughput sequencing (HTS), and the other half was put on 1.5\% water agar (PPA, Pronadisa Lab Conda, Madrid, Spain) with streptomycin $(100 \mathrm{mg} / \mathrm{L})$ to inhibit bacterial growth. Plates were incubated at room temperature on a laboratory bench for a maximum of $21 \mathrm{~d}$ and were checked daily for fungal colonies growing out of the seeds. If present, these were subcultured on Potato Dextrose Agar (Difco Bacto PDA, 39 g/L; ChemieBrunschwig AG, Basel, Switzerland), with $100 \mathrm{mg} / \mathrm{L}$ streptomycin, incubated at room temperature on a laboratory bench. Thereafter, fungal cultures were grouped based on the macro-morphological features of the mycelia (Ganley and Newcombe 2006).

DNA was extracted from 2-5 representative cultures of each group of morphotypes using LGC reagents and Kingfisher 96/Flex (LGC Genomics GmbH, Berlin, Germany), according to manufacturer's recommendations. The internal transcribed spacer (ITS) region was amplified with PCR in $25 \mu \mathrm{L}$ volumes, containing $2 \mu \mathrm{L}$ of DNA template, $1 \times \mathrm{H}_{2} \mathrm{O}, 0.4 \mu \mathrm{mol} / \mathrm{L}$ of each of the modified ITS1 and ITS4 primers developed by Tedersoo et al. (2014) and $1 \times$ JumpStart REDTaq ReadyMix Reaction Mix (Sigma-Aldrich). PCR was carried out on a Veriti 96-Well Thermal Cycler (Applied Biosystems) with the following settings: $2 \mathrm{~min}$ at $94^{\circ} \mathrm{C}$, followed by 35 cycles of $30 \mathrm{~s}$ at $94^{\circ} \mathrm{C}, 30 \mathrm{~s}$ at $55^{\circ} \mathrm{C}, 1 \mathrm{~min}$ at $72^{\circ} \mathrm{C}$, and a final extension of $10 \mathrm{~min}$ at $72^{\circ} \mathrm{C}$. Successful amplification was confirmed by agarose gel electrophoresis, and PCR products were sent to Macrogen (Amsterdam, Netherlands) for purification and Sanger sequencing. The resulting sequences were aligned and edited using CLC DNA Workbench (Qiagen). Sequences were taxonomically classified based on the ITS2 region with a naïve Bayesian classifier implemented in MOTHUR against the UNITE database (Nilsson et al. 2019 ) with a minimum bootstrap support of $80 \%$.

\section{Fungal assessment by high-throughput sequencing (HTS)}

Seed-borne fungal communities of all 58 seed lots were also assessed using an HTS approach (Appendix S1: Table S1). The set-aside halves of the surface sterilized seeds from each seed lot were pooled and ground using a batch mill Tube Mill (IKA-Werke GmbH \& Co. $\mathrm{KG}$, Staufen, Germany) or with a pestle and mortar, under liquid nitrogen, if the seeds were small. DNA was extracted from $50 \mathrm{mg}$ of ground seeds from each seed lot using DNeasy PowerPlant Pro Kit (Qiagen) following the manufacturer's instructions. This kit was used because it contains Phenolic Separation Solution, which improves the DNA yield from samples rich in phenols, such as some tree seeds. We used $40 \mu \mathrm{L}$ of the solution for each sample, as recommended in the manufacturer's instructions. DNA concentrations were quantified using the Qubit dsDNA BR Assay Kit (Thermo Fisher Scientific, Waltham, USA) on a Qubit 3.0 Fluorometer (Thermo Fisher Scientific), and DNA was diluted to $10 \mathrm{ng} / \mu \mathrm{L}$. Samples that yielded $<10 \mathrm{ng} / \mu \mathrm{L}$ were not diluted. The internal transcribed spacer region 2 (ITS2) was amplified with the 5.8S-Fung and ITS4-Fung primers (Taylor et al. 2016). PCR amplifications were performed in $20 \mu \mathrm{L}$ reaction volumes containing $50 \mathrm{ng}$ of DNA template, $1 \mathrm{mg} / \mathrm{mL}$ BSA, $1 \mathrm{mmol} / \mathrm{L}$ of $\mathrm{MgCl}_{2}$, $0.4 \mu \mathrm{mol} / \mathrm{L}$ of each primer, and $0.76 \times$ JumpStart REDTaq ReadyMix Reaction Mix (Sigma-Aldrich). PCR was carried out using Veriti 96-Well Thermal Cycler (Applied Biosystems) with the following settings: 2 min at $94^{\circ} \mathrm{C}$; followed by 35 cycles of $30 \mathrm{~s}$ at $94^{\circ} \mathrm{C}, 30 \mathrm{~s}$ at $58^{\circ} \mathrm{C}$, and $2 \mathrm{~min}$ at $72^{\circ} \mathrm{C}$; and a final extension of $10 \mathrm{~min}$ at $72^{\circ} \mathrm{C}$. Each sample was amplified in triplicates and successful PCR amplification confirmed by agarose gel electrophoresis before and after pooling the triplicates. Pooled amplicons were sent to the Génome Québec Innovation Center at McGill University (Montréal, Quebec, Canada) for barcoding using Fluidigm Access Array technology (Fluidigm, South San Francisco, California, USA) and paired-end sequencing on the Illumina MiSeq v3 platform (Illumina, San Diego, California, USA). 


\section{Sequence quality filtering, Exact Sequence Variant}

(ESV) clustering and taxonomic assignments

Sequence quality filtering, ESV clustering and taxonomic assignments were done on a bigger data set that consisted of the sequences obtained from the traded seed material (58 seed lots), and seeds collected in botanical gardens in Europe and North America (85 seed lots; Franić et al.. unpublished manuscript), as described below. For the purposes of this manuscript, the final sample x ESV matrix was filtered so it contained only samples (seed lots) and corresponding ESV abundances obtained from traded seed material.

Quality filtering and clustering into ESVs (Callahan et al. 2017) was done with a customized pipeline largely based on UPARSE (Edgar 2013) implemented in USEARCH v.8 (Edgar 2010). Pair-end reads were merged using the USEARCH fastq_mergepairs algorithm (Edgar and Flyvbjerg 2015) with a required overlap of at least 30 base pairs and a minimum length of the merged sequence of $150 \mathrm{bp}$. PhiX fragments were removed using the nophix function built into USEARCH. PCR primers were detected and removed using Cutadapt (Martin 2011) allowing for one mismatch. Reads not matching the primers were discarded. The USEARCH fastq_filter (Edgar and Flyvbjerg 2015) function was used for quality filtering based on error probabilities, with a maximum expected error threshold of one. Sequences were de-replicated and all reads below an abundance threshold of four and chimeric sequences were discarded using USEARCH fastx_uniques. Seque nces were clustered into ESVs using the UNOISE2 algorithm built into USEARCH with an alpha value of 2 (Edgar 2016). The final ESV sequences were checked with ITSx (Bengtsson-Palme et al. 2013), and sequences not verified as ITS2 regions were discarded. The final sample x ESV matrix was obtained by mapping all quality filtered reads against the ESV sequences using the usearch_global algorithm built into USEARCH with the search criteria of maxrejects 0 , maxaccepts 0 and top_hit_only. Taxonomical classification of ESVs was performed using the naïve Bayesian classifier (Wang et al. 2007) implemented in MOTHUR (Schloss et al. 2009), with a minimum bootstrap support of $80 \%$. ESV sequences were first compared against a customized ITS2 reference database collected from NCBI GenBank to exclude non-fungal sequences. Taxonomic affiliation of the fungal sequences was then obtained by querying against the UNITE database (Nilsson et al. 2019).

\section{Comparison of plating and HTS}

To determine if the fungal community detected by plating represents a subset of the fungal community captured by HTS, we mapped the ITS2 region of sequenced fungal cultures against the ITS2 region of the ESV sequences using the usearch_global algorithm built into USEARCH.

\section{Identification of potential fungal pathogens}

Parsing of fungal ESVs into guilds was done based on their taxonomic assignments by using the FUNGuild tool (Nguyen et al. 2016). FunGuild consists of a community-annotated data base and a bioinformatic script that assigns taxonomic names to functional guilds. Since we aimed at detecting all plant pathogens, the output table (Appendix S2: Table S1) was filtered by selecting all combinations of guilds in which plant pathogens were mentioned. For all ESVs that could be identified to species and that were recognized as potential plant pathogens, a literature search was done for reports or studies on their pathogenicity, known woody plant hosts and distribution range. For this, the Fungal Databases, U.S. National Fungus Collections, ARS, USDA (Farr and Rossman 2019), were used. Fungal cultures were parsed into guilds based on the guild of the fungal ESV they mapped with.

\section{Statistical analyses}

All statistical tests were performed using R (R Core Team 2018) and were considered significant at $P<0.05$. Seed lots were the unit of analysis for all statistics. Comparisons were made between different groups (angiosperms and gymnosperms) and origins (Europe, Asia, and North America) of seed lots. The means and standard errors for the number of seeds infested with fungi per seed lot, and fungal infestation and diversity at the level of tree species are given in Appendix S3: Table S1.

We tested the effect of seed origin or taxonomic group on infestation rates by insects using Hurdle models (glmmTMB function from the glmmTMB package (Brooks et al. 2017)), because the data were zero inflated. We tested for differences in overall infestation (seeds with larvae and/or exit holes), as well as in presence and number of larvae and exit holes separately. Binomial generalized linear mixed models were first used to analyze binary responses (presence or absence of larvae and exit holes). Seed lots of Asian origin were excluded from the analysis of exit holes because they did not show any exit holes. Truncated Poisson generalized linear mixed models were then fitted to the number of larvae and exit holes for those seed lots with insects or exit holes. In all models, taxonomic group (angiosperms and gymnosperms) and origin (Asia, Europe, North America) were fixed effects and tree species a random effect. Interactions were not included in these analyses.

The differences in the number of fungal cultures, morphotypes and ESVs among seed lots were analysed with the same fixed and random effect variables as mentioned above, but including interactions. We assumed a negative binomial distribution for the errors of these response variables, because Poisson models were overdispersed. The differences in percentages of potentially pathogenic ESVs and ESVs not identified to genus or species, as a 
percentage of total ESVs per seed lot, were tested with models containing the same fixed and random effects, including interactions. For these models, we assumed a beta-binomial distribution for the errors because binomial models were overdispersed. A Tukey comparison of least-squares means was performed with the function lsmeans from the lsmeans package (Lenth 2016). The same function was used to calculate mean values and standard errors for fixed effects in the models.

To test the differences between fungal communities associated with seeds of different taxonomical groups and origins multivariate generalized linear models (multivariate GLMs) were fitted to the ESV abundance matrix. This approach was used because, unlike distancebased approaches such as PERMANOVA, multivariate GLMs account for the mean-variance relationship (Warton et al. 2012). The matrix was previously standardized across samples by randomly subsampling each sample to the lowest number of read counts obtained by any sample (here 7,038 read counts) to account for different sequencing depth across samples. Generalized linear models were fitted with the function manyglm from the mvabund package (Wang et al. 2012). Negative binomial distribution of sequence counts was assumed.

The differences in seed size among different groups and origins were assessed with the function lmer from the lme4 package (Bates et al. 2015) with log-transformed seed size as the response variable and the same fixed and random effect variable as above, including interactions. Angiosperm seeds were significantly larger than gymnosperm seeds $(43.51 \pm 20.72$ and $10.13 \pm 3.54 \mathrm{~mm}^{2}$, respectively [mean $\left.\pm \mathrm{SE}\right] ; \chi^{2}=5.78$, $\mathrm{df}=1, P=0.016$ ) but no differences in seed size were found among the different origins $\left(\chi^{2}=0.43, \mathrm{df}=2\right.$, $P=0.808)$. The relationship between the average size of the seeds in a seed lot and the number of fungal cultures per seed lot, number of morphotypes per seed lot and the number of fungal ESVs per seed lot and was tested using glmmTMB, again with tree species as a random effect. A negative binomial distribution for the errors was assumed because Poisson models were overdispersed.

The relationship between the number of fungal morphotypes and ESVs per seed lot was tested using Spearman correlations. All seed lots in which fungi were assessed with both methods, plating and HTC (Appendix S1: Table S1), were included in this analysis.

\section{Results}

\section{Insect assessment}

Infestation. - Around $50 \%$ of the seed lots were infested, i.e., they contained larvae or had exit holes, but no differences in the infestation rate were found among seed lots of different groups or origins $(50.58 \pm 14.86 \%$ [overall mean \pm SE]; Appendix S4: Table S1).

Nearly $30 \%$ of the seed lots contained insect larvae, with a total of 79 individuals detected. Insects were found in seed lots of only four tree species: Larix gmelinii (Rupr.) Kuzen., P. abies, Q. garryana, and T. heterophylla (Table 2). The number of larvae per seed lot corresponded to the number of infested seeds per seed lot (i.e., one larva per infested seed), except for Q. garryana $(5.5 \pm 0.9$ infested seeds per seed lot) where sometimes more than one larva was found per seed. No differences in the presence or number of larvae were detected between angiosperm and gymnosperm seed lots, or between seeds of different origins (Appendix S4: Table S1).

Exit holes were recorded in around $30 \%$ of seed lots. A higher percentage of angiosperm than gymnosperm seed lots contained exit holes $(73.06 \% \pm 10.46 \%$ and $11.75 \% \pm 6.43 \%$, respectively; Appendix S4: Table S1) but the origins did not differ in the percentage of seed lots that contained exit holes (Appendix S4: Table S1). The number of exit holes per seed lot did not depend on taxonomic group or origin (Appendix S4: Table S1).

Diversity. - The 79 insect larvae belonged to four orders, namely Hymenoptera (48.1\%), Lepidoptera (31.6\%), Coleoptera (15.2\%), and Diptera (2.5\%), with two specimens $(2.5 \%)$ unidentified. Hymenopteran and dipteran larvae were found only in gymnosperms, and lepidopteran and coleopteran larvae only in angiosperm seeds. Molecular analyses allowed the identification of 45 larvae to species, with a match of at least $99 \%$ in the barcode database (Table 3). Additionally, 12 specimens were identified to genus and two to the family level (Table 3). Two specimens could not be classified based on morphological features or by sequencing.

\section{Fungal assessment by plating}

Infestation.-Plating yielded fungal cultures from around $96 \%$ of the seed lots. No fungi developed on agar from

TABLE 2. Infestation of seed lots by insects calculated as percentage of seed lots containing larvae and average number of larvae per seed lot (SL) of tree species that contained insect (mean $\pm \mathrm{SE}$ ).

\begin{tabular}{lllcc}
\hline \hline Tree species & \multicolumn{1}{c}{ Origin } & Group & SL with larvae (\%) & Larvae density (no. larvae/SL) \\
\hline Larix gmelinii & Asia & Gymnosperm & $100.0 \pm 0.0$ & $1.7 \pm 0.3$ \\
Picea abies & Europe & Gymnosperm & $80.0 \pm 20.0$ & $5.8 \pm 2.3$ \\
Quercus garryana & North America & Angiosperm & $83.3 \pm 16.7$ & $6.2 \pm 2.4$ \\
Tsuga heterophylla & North America & Gymnosperm & $57.1 \pm 20.2$ & $1.1 \pm 0.6$ \\
\hline
\end{tabular}


TABLE 3. Insect taxa found in traded seed lots from different continents.

\begin{tabular}{|c|c|c|c|c|c|}
\hline Identified taxon & Insect order & $\begin{array}{l}\text { Number of } \\
\text { specimens }\end{array}$ & Europe & North America & Asia \\
\hline Cecidomyiidae sp. $\dagger$ & Diptera & 2 & 61,62 & & \\
\hline Curculio sp: $\$$ & Coleoptera & 8 & & $17,20,21$ & \\
\hline Cydia latiferreana Walsingham & Lepidoptera & 25 & & $17,18,19,20,21$ & \\
\hline Eurytoma sp. $\S$ & Hymenoptera & 1 & & & 30 \\
\hline Megastigmus pictus Förster & Hymenoptera & 2 & & & 28,68 \\
\hline Megastigmus strobilobius Ratzeburg & Hymenoptera & 15 & $59,60,61,62$ & & \\
\hline Megastigmus tsugae Crosby & Hymenoptera & 3 & & $7,51,67$ & \\
\hline Megastigmus sp.ף & Hymenoptera & 1 & 61 & & \\
\hline
\end{tabular}

Note: The match between specimens' query and the reference sequence is more than $99 \%$, unless stated otherwise. The numbers under the origins indicate the seed lots (Appendix S1: Table S1) in which the species were found.

$\uparrow 94-95 \%$ identity match with Cecidomyiidae.

$\$ 92-93 \%$ identity match with Curculio sulcatulus Schrank.

$\S 95.62 \%$ identity match with Eurytoma laricis Yano.

- $97.26 \%$ identity match with $M$. strobilobius.

two European seed lots (P. abies SL 24 and P. sylvestris SL 22). The number of fungal cultures varied with both origin and taxonomic group: overall, angiosperms yielded more fungal cultures per seed lot than gymnosperms and European seed lots had the most and North American seed lots the fewest fungal cultures. Differences between taxonomic groups also varied with origin: European angiosperms yielded more than 10 times as many fungal cultures as European gymnosperms (Appendix S4: Table S2), while Asian and North American angiosperms only had two to three times more fungal cultures than gymnosperms from the same continent (Fig. 1; Appendix S4: Table S2). The number of fungal cultures per seed lot was not affected by the size of the seeds in a seed lot $\left(\chi^{2}=0.36, \mathrm{df}=1, P=0.548\right)$ and this was

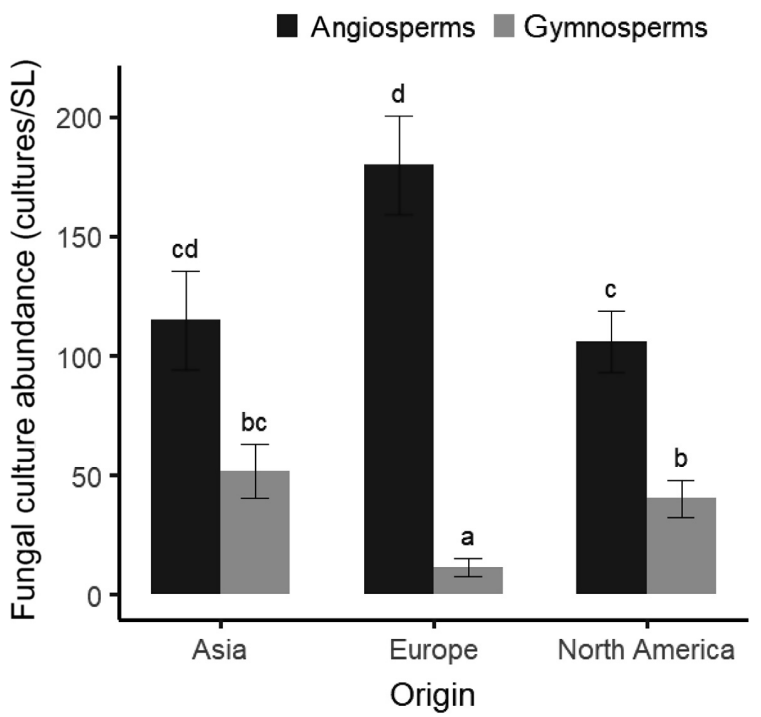

FIG. 1. Number of fungal cultures in seed lots (SL) of different groups and origins. Different letters above the bars indicate significantly different values $(P<0.05)$. Values are mean and SE. consistent among angiosperms and gymnosperms (Group $\times$ Seed size: $\chi^{2}=1.75, \mathrm{df}=1, P=0.185$ ).

Diversity.-A total of 4,202 fungal cultures were obtained from plated seeds. Overall, angiosperms had more fungal morphotypes per seed lot than gymnosperms. The origin of the seeds also had a significant effect, with European seed lots having the largest and North American seed lots having the lowest number of fungal morphotypes per seed lot. The number of fungal morphotypes per group also varied with origin: angiosperms had more morphotypes than gymnosperms in Europe but not in North America or Asia (Fig. 2; Appendix S4: Table S2). The number of fungal morphotypes per seed lot was not affected by the size of the seeds $\left(\chi^{2}=0.09\right.$, df $\left.=1, P=0.768\right)$ and this was consistent among angiosperms and gymnosperms (Group $x$ Seed size: $\chi^{2}=1.26, \mathrm{df}=1, P=0.262$ ).

A total of $473(11.3 \%)$ fungal cultures out of 4,202 recovered from seeds were sequenced. Good quality sequences were obtained from 441 cultures $(93 \%)$. These sequences belonged to the classes Ascomycota (96\%), Mucoromycota (2.5\%), and Basidiomycota (1.5\%). A total of $295(66.9 \%)$ sequences were identified to one of 42 identified genera, and $142(32.2 \%)$ to one of 53 identified species. In around $50 \%$ of the cases where two to five cultures of the same morphotype were sequenced, all sequences were mapped to the same ESV, around $70 \%$ were identified as the same genus and $75 \%$ to the same family.

Potential fungal pathogens. - A total of 107 out of 473 sequenced fungal cultures were assigned to one of 21 potentially plant pathogenic fungal genera, and of those, 51 fungal cultures to 18 potentially plant pathogenic fungal species (Table 4). Among these, two potentially plant pathogenic fungal species known to be associated with woody plants and absent from or with a limited distribution in Europe were identified, namely Diaporthe 




FIG. 2. Number of fungal morphotypes in seed lots (SL) of different groups and origins. Different letters above the bars indicate significantly different values $(P<0.05)$. Values are mean and SE.

alleghaniensis R.H. Arnold (L. gmelinii SL 28) and Microascus cirrosus Curzi (P. abies SL 61).

Fungal assessment by high-throughput sequencing (HTS)

Infestation and diversity.-All 58 seed lots analysed using HTS were infected by fungi. The 2,376,400 high quality sequences $(40,972 \pm 1,595$ reads per seed lot) clustered into 1,905 Exact Sequence Variants (ESVs) $(119.9 \pm 9.8$ ESVs per seed lot). Overall, angiosperm seed lots had more fungal ESVs than gymnosperm seed lots and Asian seed lots had more fungal ESVs than seed lots from Europe and North America (Fig. 3; Appendix S4: Table S2). The number of fungal ESVs per seed lot increased with seed size $\left(\chi^{2}=3.93\right.$, df $=1$, $P=0.047$ ), and angiosperms had larger seeds and more fungal ESVs than gymnosperms $\left(\chi^{2}=35.48\right.$, $\mathrm{df}=1$, $P<0.001)$.

Around $72 \%(1,365$ out of 1,905$)$ of the ESVs were assigned to the Ascomycota, 18\% (340) to the Basidiomycota, $<1 \%$ (12) to the Mucoromycota, and 9\% (188) ESVs remained unclassified. A total of $1143(60 \%)$ and $559(30 \%)$ ESVs were assigned to 234 genera and 269 species, respectively.

Overall, gymnosperms, especially those from Europe, had a higher percentage of ESVs not identified to the genus level than angiosperms $(44.15 \pm 1.89$ and $30.74 \pm 1.84$, respectively) (mean \pm SE; Appendix S4: Table S2). However, the percentage of ESVs not identified to the species level was similar among groups and origins (Fig. 4; Appendix S4: Table S2).

Fungal communities differed significantly among seed lots of different taxonomic groups $(\mathrm{df}=1$, deviance $=5921, \quad P=0.001)$ and seed origins $(\mathrm{df}=2$,
TABLE 4. Fungal genera and species known to be potentially plant pathogenic that were found in traded seed lots from different continents.

\begin{tabular}{|c|c|c|c|}
\hline \multirow{2}{*}{$\begin{array}{l}\text { Plant pathogenic } \\
\text { genus/species }\end{array}$} & \multicolumn{3}{|c|}{$\begin{array}{l}\text { Number and origin of fungal } \\
\text { cultures }\end{array}$} \\
\hline & Europe & North America & Asia \\
\hline Alternaria & 2 & 3 & 5 \\
\hline Aureobasidium & & 1 & \\
\hline Botryosphaeria & & & 3 \\
\hline Ceratobasidium & 1 & & \\
\hline Cladosporium & & 1 & \\
\hline Colletotrichum & 1 & & 2 \\
\hline Cryptodiaporthe & & 1 & \\
\hline Cytospora & & 4 & \\
\hline Diaporthe & 4 & & 5 \\
\hline Didymella & & & 2 \\
\hline Fusarium & & 2 & 3 \\
\hline Gibberella & 6 & 5 & 3 \\
\hline Pestalotiopsis & & 1 & \\
\hline Trichothecium & & 1 & \\
\hline $\begin{array}{l}\text { Aequabiliella effuse (Damm } \\
\& \text { Crous) Crous }\end{array}$ & & & 1 \\
\hline $\begin{array}{l}\text { Alternaria eichhorniae Nag } \\
\text { Raj \& Ponnappa }\end{array}$ & 1 & & 2 \\
\hline $\begin{array}{l}\text { Cladosporium exasperatum } \\
\text { Bensch, Summerell, Crous } \\
\text { \& U. Braun }\end{array}$ & 1 & 3 & \\
\hline Cytospora ribis Ehrenb. & 2 & 4 & \\
\hline $\begin{array}{l}\text { Diaporthe alleghaniensis } \\
\text { R.H. Arnold }\end{array}$ & & & 1 \\
\hline $\begin{array}{l}\text { Diaporthe cotoneastri } \\
\text { (Punith.) Udayanga, PW } \\
\text { Crous and KD Hyde }\end{array}$ & & 2 & 1 \\
\hline $\begin{array}{l}\text { Diatrypella atlantica D.A.C. } \\
\text { Almeida, Gusmão \& A.N. } \\
\text { Mill. }\end{array}$ & & 1 & \\
\hline $\begin{array}{l}\text { Didymella heteroderae (Sen } \\
\text { Y. Chen, D.W. Dicks. \& } \\
\text { Kimbr.) Qian Chen \& L. } \\
\text { Cai }\end{array}$ & 5 & 3 & \\
\hline Diplodia seriata De Not. & 1 & 1 & \\
\hline $\begin{array}{l}\text { Fusarium fujikuroi } \\
\text { Nirenberg }\end{array}$ & & & 1 \\
\hline $\begin{array}{l}\text { Gibberella pulicaris (Fr.) } \\
\text { Sacc. }\end{array}$ & 3 & & \\
\hline Gibberella tricincta El-Gholl & 5 & 4 & \\
\hline Microascus cirrosus Curzi & 1 & & \\
\hline $\begin{array}{l}\text { Neofusicoccum parvum } \\
\text { (Pennycook \& Samuels) } \\
\text { Crous, Slippers \& A.J.L. } \\
\text { Phillips }\end{array}$ & & & 1 \\
\hline $\begin{array}{l}\text { Ophiostoma nigrocarpum } \\
\text { (R.W. Davidson) de Hoog }\end{array}$ & 1 & & \\
\hline $\begin{array}{l}\text { Pestalotiopsis coffeae- } \\
\text { arabicae Y. Song, K. Geng, } \\
\text { K.D. Hyde \& Yong Wang } \\
\text { bis }\end{array}$ & & & 4 \\
\hline $\begin{array}{l}\text { Pestalotiopsis malayana } \\
\text { Maharachch., K.D. Hyde } \\
\text { \& Crous }\end{array}$ & & & 1 \\
\hline $\begin{array}{l}\text { Pezicula neosporulosa Y. } \\
\text { Zhilin \& G.J.M. Verkley }\end{array}$ & 1 & & \\
\hline
\end{tabular}

Note: Numbers indicate number of recovered cultures for each genus or species and continent. 


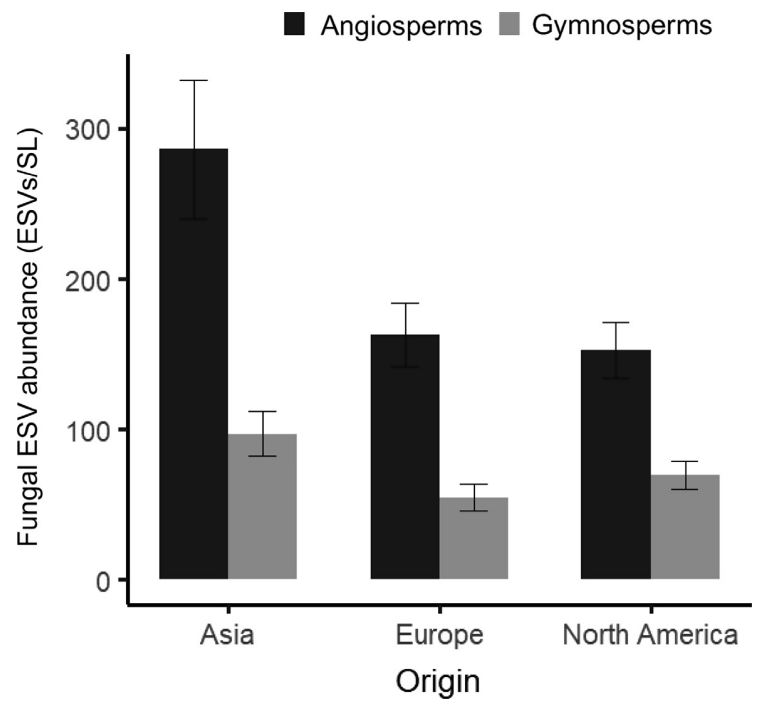

FIG. 3. Number of fungal exact sequence variants (ESVs) in seed lots (SL) of different groups and origins. Values are mean and SE.

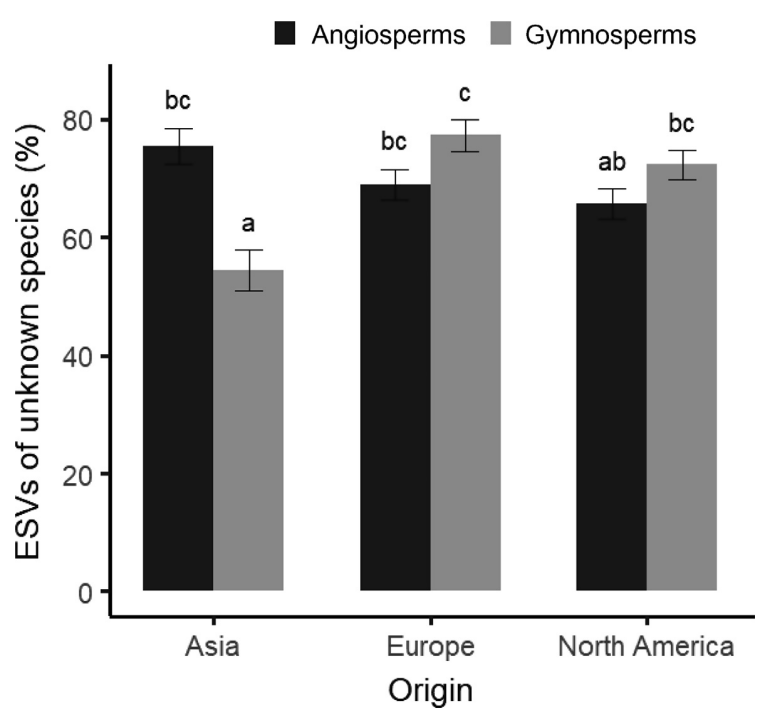

FIG. 4. Percentage of fungal ESVs not identified to the species level in seed lots of different groups and origins. Different letters above the bars indicate significantly different values $(P<0.05)$. Values are mean and SE.

deviance $=7216, P=0.001)$ A total of 1,099 out of 1,905 ESVs $(58 \%)$ were found exclusively in angiosperm seeds and $444(23 \%)$ only in gymnosperm seeds. Only $362(19 \%)$ ESVs were found to be associated with seeds of both groups. Around $65 \%$ of ESVs were unique to one continent and $12 \%$ of the ESVs were found in seed lots from all three continents. Europe and North America shared more than two times as many ESVs (14\%) than either continent shared with Asia (4.8\% and 4.3\%, respectively).
Potential fungal pathogens. - A total of 532 out of 1,905 ESVs (28\%) were not assigned to a guild, and 630 out of 1,905 ESVs were classified as potentially pathogenic (33\%). A total of 508 out of 1,905 ESVs were assigned to one of 86 potentially plant pathogenic fungal genera and of those, 182 ESVs to 100 potentially plant pathogenic fungal species. No differences in the relative occurrence of potentially plant pathogenic ESVs were found among continents $(37.67 \% \pm 2.06 \%$; Appendix S4: Table S2), but angiosperms had a higher percentage of potentially plant pathogenic ESVs than gymnosperms $(48.53 \pm 3.28$ and $26.81 \pm 2.50, \quad$ respectively; Appendix S4: Table S2). Eight and three of the potentially pathogenic fungal species, which are known to be associated with woody plants, are absent or have a restricted distribution in Europe, respectively (Table 5).

\section{Comparison of fungal assessment by plating and HTS}

The number of fungal morphotypes per seed lot was positively correlated with the number of fungal ESVs per seed lot $(r=0.59, S=10170, P<0.001)$. All but one of the 441 sequences of good quality from fungal cultures mapped against 126 ESV centroids from HTS. A total of 350 out of 441 sequences had an identical match to ESV sequences, and only 15 had a match of $<80 \%$. Around $6 \%$ of fungal diversity assessed by HTS (1,905 ESVs) was captured by plating (126 ESVs).

Similar fractions of pathogenic ESVs were obtained by plating (59 out of 126 ESVs, 47\%) and using HTS (630 out of 1,905 ESVs, 33\%).

Ten fungal species that are known to be associated with woody plant hosts and are absent or have limited distribution in Europe were identified by HTS only (Table 5), D. alleghaniensis was identified by HTS and plating and $M$. cirrosus was identified only by plating.

\section{Discussion}

The trade in seeds of most tree species is not regulated because seeds are considered less likely to carry harmful organisms than other plants for planting (P4P). However, our results demonstrate that seeds contain many insects and fungi. The high infestation of commercially supplied seed lots is a clear indication of how often potential pests may be transported via traded seeds. Furthermore, the presence of organisms that are already known to be pests in these seeds indicates that measures should be taken to reduce pest risk.

\section{Risk of pest introduction}

The absence of significant differences in insect infestation levels between taxonomic groups and origins of the seeds suggests that movement of potential pests occurs in all directions and in both angiosperms and gymnosperms. Since all insect species identified in this study are highly host specific, the higher percentage of seed 
TABLE 5. Fungal species known to be potential pathogens of woody plants, found in traded seed lots from different continents.

\begin{tabular}{|c|c|c|c|c|}
\hline \multirow[b]{2}{*}{ Plant pathogenic species } & \multirow{2}{*}{$\begin{array}{l}\text { Corresponding } \\
\text { ESV }\end{array}$} & \multicolumn{3}{|c|}{ Origin of seed lots } \\
\hline & & Europe & North America & Asia \\
\hline \multicolumn{5}{|l|}{ Absent from Europe } \\
\hline Alternaria rosae E.G. Simmons \& C.F. Hill & ESV0248 & 57,73 & $11,12,50$ & \\
\hline Colletotrichum gigasporum Rakotonir. \& Munaut & ESV2475 & & & $29,75,77$ \\
\hline Diaporthe australafricana Crous \& Van Niekerk & ESV0675 & 57,78 & $5,7,10,11,14,15$ & \\
\hline Diaporthe siamensis Udayanga, X. Z. Liu \& K.D. Hyde & ESV1811 & & & 77 \\
\hline Lasiodiplodia crassispora T. Burgess \& Barber & ESV0546 & & & $27,29,74,75,76$ \\
\hline $\begin{array}{l}\text { Phaeoacremonium roseum J.R. Úrbez-Torres, P. Haag \& } \\
\text { D.T. O'Gorman }\end{array}$ & ESV0482 & & $16,17,20$ & 77 \\
\hline $\begin{array}{l}\text { Pseudocercospora sphaerellae-eugeniae (Rangel) Crous, } \\
\text { Alfenas \& R.W. Barreto }\end{array}$ & $\begin{array}{l}\text { ESV0479 } \\
\text { ESV0731 } \\
\text { ESV0856 } \\
\text { ESV1113 } \\
\text { ESV1721 } \\
\text { ESV2598 }\end{array}$ & & & 75,77 \\
\hline \multicolumn{5}{|l|}{ Limited distribution in Europe } \\
\hline Diplodia corticola A.J.L. Phillips, A. Alves \& J. Luque & ESV2722 & & 19 & 75 \\
\hline Neonectria major (Wollenw.) Castl. \& Rossman & ESV0139 & 63 & & \\
\hline Setomelanomma holmii M. Morelet & ESV0362 & 71,73 & & 30 \\
\hline Diaporthe alleghaniensis R.H. Arnold & $\begin{array}{l}\text { ESV1258 } \\
\text { ESV2757 }\end{array}$ & 73 & & $28,30,68,74$ \\
\hline
\end{tabular}

Notes: New records for species-continent combinations are identified by boldface type. Numbers indicate the seed lots (Appendix S1: Table S1) in which the species were found. ESV, exact sequence variant.

lots showing exit holes in angiosperm than gymnosperm seeds may be due to the biology of the insects. Specifically, larvae of $C$. latiferreana and of Curculio sp. were still found in $Q$. garryana acorns, whereas seeds of the other angiosperms only had exit holes. This indicates that larvae had been in the seeds, but left them to pupate before the seeds were traded. On the other hand, in gymnosperm seeds we detected mainly hymenopteran seed pests (Megastigmus species), which are known to spend their entire life cycle in the seeds and cannot be detected by external observation (Roques et al. 2003). These gymnosperm pests are therefore of greater phytosanitary risk than angiosperm insects, which usually leave the seeds to pupate in the soil.

Three insect species of phytosanitary concern have been identified in this study. The chalcid wasp Megastigmus strobilobius Ratzeburg is a native pest of northern Eurasian Picea species (P. abies and Picea obovata Ledeb.), but has now colonized plantations of its native hosts from Western Europe to the Lake Baikal (Roques and Skrzypczyńska 2003). Similarly, Megastigmus tsugae Crosby is known to infest seeds of T. heterophylla and Tsuga mertensiana (Bong.) Carr. in the North American range of these hemlocks, but has never been recorded in native or planted hemlocks in Asia or Europe (Roques and Skrzypczyńska 2003, Roques et al. 2003). The chalcid wasp Megastigmus pictus Förster is a specialist of the Eurasian larch species (Larix spp.) with a wide distribution in Europe and Asia (Roques and Skrzypczyńska 2003) but had not previously been documented in North America. This is probably also the case for the unidentified Eurytoma sp. found in Chinese seeds of L. gmelinii, the sequence of which is similar to Eurytoma laricis Yano, a common Eurasian larch seed chalcid. A specimen of the American M. tsugae was found in Tsuga seeds that were purchased from European suppliers, and a specimen each of the Eurasian $M$. pictus and E. laricis were found in L. gmelinii seeds purchased in North America. These results therefore provide evidence for movement of potential pests via the seed trade to the areas where they were previously not recorded.

Fungi were more frequent in seed lots than insects were, and more frequent in seeds of a seed lot than insects were (Appendix S3: Table S1), which indicates that the likelihood of introducing fungi is higher than the likelihood of introducing insects. However, the likelihood that an introduced insect is a pest appears higher than the likelihood of an introduced fungus being a pathogen. This is due to the majority of seed-borne fungi being commensalic or beneficial species, while the seedborne insects are all specialized herbivores. Moreover, while all insects that we extracted from the seeds were alive, we can only be sure that the fungi plated on agar were living. Since DNA is detectable for several weeks to months after the organisms' death (Schena et al. 2004), we cannot be sure that Exact Sequence Variants (ESVs) detected by high-throughput sequencing (HTS) originated from living structures (e.g., spores, mycelia) and detection of DNA without evidence of viability of the pest would be insufficient reason to adopt specific restrictive measures in the phytosanitary context of international trade (Griffin 2012). Fungal cultures of $M$. cirrosus and D. alleghaniensis, which were isolated and 
grown on agar, are therefore the only two fungal pathogens of woody plants that were certainly alive. HTS allowed the characterization of highly diverse fungal communities, including rare, slow growing, or unculturable fungi (e.g., biotrophs) and thus represents a step forward from traditional plating. However, only a small percentage of fungal ESVs could be identified to the species level due to incomplete reference sequences limiting the use of this method for phytosanitary purposes (Tedersoo et al. 2019). For illustration, in our study nearly $70 \%$ of all ESVs remained unidentified to the species level. Since pest risk assessment is usually done at the species level, these ESVs could not be used to assess phytosanitary risk.

Large differences in fungal diversity among seeds of different taxonomic groups and origins were found using HTS and plating. The hypothesis that angiosperm seeds harbor a higher fungal diversity than gymnosperm seeds was confirmed, both by plating and HTS analyses. The larger size of angiosperm seeds compared to gymnosperm seeds may account for this difference, as suggested by significant relationship between seed size and fungal diversity as assessed by HTS. The high variability of the number of fungal cultures and morphotypes and seed size among and within angiosperm and gymnosperm species is the most probable reason why we found no effect of seed size on the number of fungal cultures and morphotypes. The difference in fungal diversity might also be due to the fact that angiosperms are taxonomically more diverse than gymnosperms and thus could support a higher diversity of associated organisms. The use of HTS might have underestimated the diversity in angiosperm seeds, since a smaller fraction of the ground and mixed material was used for the assessment than for the smaller gymnosperm seeds, where sometimes all ground material was used. The differences in fungal diversity among angiosperms and gymnosperms could also be due to the different plant resistance strategies (Eyles et al. 2010, Zalamea et al. 2018), which still needs to be explored.

Angiosperm seeds harbored more unique and more potentially plant pathogenic ESVs than gymnosperm seeds, which indicates a relatively higher phytosanitary risk associated with their trade. This finding is supported by previous studies, where $58 \%$ of invasive forest pathogens in Europe were shown to be specialized on angiosperms and only $26 \%$ on gymnosperms (Santini et al. 2013). The relatively higher fungal diversity, as assessed by HTS, in Asian seeds than in North American and European seeds indicates potentially higher phytosanitary risk associated with them. The same pattern of higher biodiversity in Eastern Asia than in Europe and North America has already been shown for many other groups, such as plants (Kreft and Jetz 2007) and soil fungi (Tedersoo et al. 2014). The largest fraction of fungal ESVs was shared between European and North American seeds, which can be explained by the more intense history of trade in P4P between Europe and
North America. Hence, the European invasion debt for Asian species seems to be larger than for North American species (Rouget et al. 2016). Consequently, we expect that new nonnative fungi will be imported to Europe and North America from Asia.

\section{Risk of pest establishment}

Only a small fraction of the insects and fungi detected in the seeds are likely to become established in the region of introduction. Successful establishment requires that the insect or fungus exits the seed at its destination and infects a new, susceptible host. Moreover, specific biological characteristics make some species better invaders than others. For instance, some species of chalcid wasps, such as $M$. pictus, found in Larix seeds from China, show thelytokous parthenogenesis and a single female may be enough to establish a new population (Boivin et al. 2014). In addition, many Megastigmus spp. have the possibility to extend their state of diapause to overcome periods of adverse conditions (Turgeon et al. 1994). Megastigmus chalcids are usually oligophagous but strictly related to a tree genus (Roques et al. 2003), however, suitable hosts for all identified Megastigmus species are probably available in the three regions. For example, $M$. strobilobius has been found to parasitize seeds of a number of Asian Picea species and North American Picea pungens Engelm. in arboreta in France and Denmark (da Ros et al., 1993; Roques and Skrzypczyńska 2003), which indicates that it might switch to new hosts in Asia and North America if introduced to these regions. However, M. strobilobius as well as M. tsugae have an arrhenotokous parthenogenesis, where unmated females only produce males (Boivin et al. 2014), which limits its invasive potential.

Seed borne pests of nut-bearing angiosperms leave the nuts in autumn to pupate in the soil (Roques et al. 2003). If larvae are present in traded seeds, appropriate conditions for pupation may be lacking. Moreover, the small number of insects per seed lot, and variation in their time of emergence, may limit the chance that emerging adults find a mate and can establish a population (Contarini et al. 2009).

While a wide variety of fungi was detected and fungi were found in almost every seed lot, it is unknown whether these seed-borne organisms are seed transmitted. In general, vertical transmission of fungi in trees seems to be rare compared with seed infestation from the surrounding environment (horizontal transmission; Arnold 2007). However, for some seed-borne fungi, such as Sirococcus conigenus (Pers.) P.F. Cannon \& Minter 1983, a pathogen that causes shoot blight in numerous conifer species in North America and Europe, and the abovementioned $F$. circinatum, vertical transmission was confirmed (Sutherland et al. 1981, Storer et al. 1998, Evira-Recuenco et al. 2015). Thus, further studies would be needed to assess the potential for the detected fungi to be vertically transmitted and spread to other plants. 
The presence of a susceptible host is also essential for successful establishment of fungal species. The probability of finding a host in the introduced region is likely to decrease with increasing phylogenetic distance between the host and the native species (Gilbert and Webb 2007, Gilbert et al. 2012). Tree species of the same genera on which some of the currently absent pathogens were found also occur in Europe, such as Rosa (Alternaria rosae E.G. Simmons \& C.F. Hill), Acacia and Hibiscus (Colletotrichum gigasporum Rakotonir. \& Munaut), Corylus, Prunus, and Salix (Diaporthe australafricana Crous \& Van Niekerk), and Pistacia (M. cirrosus), which makes establishment of these pathogens possible. Some of the other pathogen species not yet present in Europe are mostly associated with hosts within tropical tree genera and/or genera from the southern hemisphere (Farr and Rossman 2019) and may be less likely to establish in Europe. However, data about host range and ecology are unavailable for many fungal species, which makes it difficult to assess their likelihood of establishment, all the more since host shifts remain difficult to predict (Gilbert and Webb 2007).

\section{Risk of post-introduction damage}

Among the identified insect species, only the filbertworm (Cydia latiferreana Walsingham) is known to cause significant damage in its current area of distribution. This moth is a major pest in commercial hazelnut (Corylus spp.) production in the northwestern United States, which relies mainly on cultivars based on European hazel (Chambers et al. 2011). Therefore, its introduction and establishment in Europe could result in serious damage of hazels. By contrast, the Megastigmus and Eurytoma infestation rates in the native range of spruce, larch and hemlock are low (Roques and Skrzypczyńska 1987, de Groot et al. 1994, Skrzypczyńska 2015) and the three identified Megastigmus species do not represent major pests of these host species. A low impact on native hosts is typical for pests in their native range (Keane and Crawley 2002). However, if an exotic pest is introduced together with its native host to an area where no congeneric hosts are present, considerable damage can occur because of the absence of natural enemies and competitors (Auger-Rozenberg and Roques 2012). For instance, the Douglas-fir seed chalcid, Megastigmus spermotrophus Wachtl, has become a major seed pest in European Douglas-fir seed orchards and plantations, whereas in its native North American range its impact is limited by its insect competitors that attack seeds earlier (Rappaport and Roques 1991). In a similar scenario, establishment of M. tsugae on T. heterophylla in Europe might considerably affect the regeneration of $T$. heterophylla.

Some of the fungal pathogens identified in this study can affect economically important woody plants occurring in Europe, and are thus of special phytosanitary concern. For example, Lasiodiplodia crassispora $\mathrm{T}$.
Burgess \& Barber, which was found in seeds of Pinus tabuliformis Carrière and Acer palmatum Thunb. from China, causes stem necrosis and cankers in grapevine (Vitis vinifera L.) in South Africa and California (ÚrbezTorres et al. 2010, van Niekerk et al. 2010). Fungus $D$. australafricana, which was found in seeds of North American Pinus, Tsuga, and Acer species, is associated with stem cankers of blueberries (Vaccinium spp.) and European hazelnut (Corylus avellane L.) in Chile (Latorre et al. 2012, Elfar et al. 2013, Guerrero and Pérez 2013). Diplodia corticola A.J.L. Phillips, A. Alves \& J. Luque, identified in seeds of North American Quercus and Asian Acer species, is responsible for cankers and dieback of oak species in North America, Northern Africa, and Southern Europe (Farr and Rossman 2019). Several of the fungal species detected are thought to be pathogens but little is known about their impact.

Current European regulations target known pest species that are absent from, or have a restricted distribution in, Europe. Yet, repeated introductions of relatively widespread species or genera can result in the formation and introduction of superior invaders (Lombaert et al. 2010, Dutech et al. 2012). Several fungal cultures of potentially pathogenic genera (e.g., Botryosphaeria, Cytospora, Diaporthe, Fusarium) and species that are already present in Europe (e.g., Cytospora ribis Ehrenb., Neofusicoccum parvum (Pennycook \& Samuels) Crous, Slippers \& A.J.L. Phillips, Diaporthe cotoneastri (Punith.) Udayanga, PW Crous and KD Hyde, Diplodia seriata De Not., Petalopsis spp.) were also recovered from non-European seeds. Similarly, a specimen of chalcid wasp M. pictus, which is known to be present in Europe, was detected in one Chinese seed lot that was imported to Europe. Admixture of naturally isolated populations of the same species can increase fitness and subsequently lead to larger and more productive populations with lower probabilities of extinction, and ultimately increase the chance of range expansion and impact (Turgeon et al. 2011, Rius and Darling 2014). Similarly, hybridization between congeneric species that are naturally isolated, might lead to formation of new, more harmful hybrids (Giordano et al. 2019) or hybrids with new or combined features obtained from their parental species (Brasier 2001). Hence, additional intraspecific or intrageneric introductions should also be avoided.

\section{Conclusions}

The results of this study, which is, to our knowledge, the first that simultaneously assessed insects and fungi associated with any type of traded P4P, strongly suggest that the trade of forest tree seeds is not as safe as previously believed. High infestation rates of seed lots of some tree species by insects and fungi, and the discovery of pests that could establish in new areas is alarming and stresses the need to reconsider phytosanitary measures in the seed trade. Measures for insects should potentially 
focus on pests of gymnosperms, since they represent a higher phytosanitary risk in comparison with insects of angiosperm seeds: the risk associated with angiosperm seed-borne insects can be significantly reduced by ensuring that seeds are collected after insects emerge but it may be more difficult to avoid gymnosperm pests. Possible measures could include improvement of detection techniques used by phytosanitary inspectors at the border, and the development of production methods to reduce infestation rates and treatments to reduce the viability of seed-borne pests.

The situation seems to be much more complex for seed-borne fungi than for insects. The high fungal abundance and diversity, especially in angiosperms and Asian seeds, which also contained large fractions of pathogenic and unique fungi, is concerning. The lack of knowledge about the distribution, host ranges, and pathogenicity of most fungal species, as well as the limitations of detection and identification techniques, make it challenging to conduct pest or pathway risk assessments. Nevertheless, our study shows that potentially serious pathogens can be found in traded seeds, and that angiosperm seeds and seeds of Asian origin might represent a particularly great risk. Since fungal pathogens are very difficult to detect during border inspections, the most promising approach might be to work on developing effective treatments for reducing their viability in seeds or to regulate the trade in seeds of especially risky origins or species. Further studies of the biology and ecology are needed for better risk assessment and management of the fungal and insect pests identified in this study.

\section{Acknowledgments}

I. Franić, E. Allan, R. Eschen, M. Kenis, and S. Prospero designed the study. M.-A. Auger-Rozenberg and A. Roques supervised the insect assessment. S. Schneider optimized molecular laboratory protocols. M. Hartmann supervised the amplicon sequencing approach and performed the bioinformatic analyses of the HTS sequence data. I. Franić analysed the data and wrote the manuscript with an input from all co-authors. We thank Quirin Kupper (WSL) for his assistance with the fungal assessment by HTS, Hélène Blauenstein, Stephanie Pfister and Sandrine Fattore (WSL) for their help with the fungal assessment by plating, Christopher Schefer (WSL) for his assistance with taking seed measures, Haley Smith (Dorena Genetic Resource Centre) and Philippe Lorme (INRA) for their help X-raying the seeds, and Valerie J. Fieland and Caroline M. Press (USDA Horticultural Crops Research Unit) for their assistance with fungal assessment of seeds obtained in North America. We are grateful to Maja Kuzman (University of Zagreb, Faculty of Science) for her advice about data manipulation in $\mathrm{R}$. We thank the Genetic Diversity Center (GDC) at ETH Zürich for providing computational infrastructure and acknowledge the contribution of scientists at the McGill University and Génome Québec Innovation Center, Montréal, Canada, for the paired-end sequencing on Illumina MiSeq. This work was supported by COST Action "Global Warning" (FP1401), We also gratefully acknowledge the financial support of the Swiss National Science Foundation (Project C15.0081) and the Swiss Federal Office for the Environment. Contributions of I. Franić, R. Eschen, and M. Kenis were supported by CABI with core financial support from its member countries (see http://www.cabi.org/about-cabi/who-we-workwith/keydonors/ for details).

\section{Literature Cited}

Anonymous. 2000. Council Directive 2000/29/EC of 8 May 2000 on protective measures against the introduction into the Community of organisms harmful to plants or plant products and against their spread within the Community.

Arnold, A. E. 2007. Understanding the diversity of foliar endophytic fungi: progress, challenges, and frontiers. Fungal Biology Reviews 21:51-66.

Arnold, A. E., and F. Lutzoni. 2007. Diversity and host range of foliar fungal endophytes: Are tropical leaves biodiversity hotspots? Ecology 88:541-549.

Auger-Rozenberg, M. A., and A. Roques. 2012. Seed wasp invasions promoted by unregulated seed trade affect vegetal and animal biodiversity. Integrative Zoology 7:228-246.

Aukema, J. E., et al. 2011. Economic impacts of non-native forest insects in the continental United States. PLoS ONE 6:1-7.

Bates, D., M. Maechler, B. M. Bolker, and S. C. Walker. 2015. Fitting linear mixed-effects models using lme4. Journal of Statistical Software 67:1-48.

Bengtsson-Palme, J., et al. 2013. Improved software detection and extraction of ITS1 and ITS2 from ribosomal ITS sequences of fungi and other eukaryotes for analysis of environmental sequencing data. Methods in Ecology and Evolution 4:914-919.

Benitez, M.-S., M. H. Hersh, R. Vilgalys, and J. S. Clark. 2013. Pathogen regulation of plant diversity via effective specialization. Trends in Ecology and Evolution 28:705-711.

Boivin, T., H. Henri, F. Vavre, C. Gidoin, P. Veber, J. N. Candau, E. Magnoux, A. Roques, and M. A. Auger-Rozenberg. 2014. Epidemiology of asexuality induced by the endosymbiotic Wolbachia across phytophagous wasp species: host plant specialization matters. Molecular Ecology Notes 23:23622375.

Boyd, I. L., P. H. Freer-Smith, C. A. Gilligan, and H. C. J. Godfray. 2013. The consequence of tree pests and diseases for ecosystem services. Science 342:823-831.

Brasier, C. M. 2001. Rapid evolution of introduced plant pathogens via interspecific hybridization. BioScience 51:123-133.

Brasier, C. M. 2008. The biosecurity threat to the UK and global environment from international trade in plants. Plant Pathology 57:792-808.

Brooks, M. E., K. Kristensen, K. J. van Benthem, A. Magnusson, C. W. Berg, A. Nielsen, H. J. Skaug, M. Mächler, and B. M. Bolker. 2017. glmmTMB balances speed and flexibility among packages for zero-inflated generalized linear mixed modeling. R Journal 9:378-400.

Burgess, T., and M. J. Wingfield. 2002. Quarantine is important in restricting the spread of exotic seed-borne tree pathogens in the southern hemisphere. International Forestry Review 4:56-65.

Callahan, B. J., P. J. McMurdie, and S. P. Holmes. 2017. Exact sequence variants should replace operational taxonomic units in marker-gene data analysis. ISME Journal 11:2639-2643.

Chambers, U., V. M. Walton, and S. A. Mehlenbacher. 2011. Susceptibility of hazelnut cultivars to Filbertworm, Cydia latiferreana. HortScience 46:1377-1380.

Cleary, M., F. Oskay, H. Tugba, S. Woodward, and A. M. Vettraino. 2019. Cryptic risks to forest biosecurity associated with the global movement of commercial seed. Forests $10: 459$.

Contarini, M., K. S. Onufrieva, K. W. Thorpe, K. F. Raffa, and P. C. Tobin. 2009. Mate-finding failure as an important cause 
of Allee effects along the leading edge of an invading insect population. Entomologia Experimentalis et Applicata 133:307-314.

da Ros, N., R. Ostermeyer, A. Roques, and J. P. Raimbault. 1993. Insect damage to cones of exotic conifer species introduced in arboreta. 1. Interspecific variations within the genus Picea. Journal of Applied Entomology 115:113-133.

de Groot, P., J. J. Turgeon, and G. E. Miller. 1994. Status of cone and seed insect pest management in Canadian seed orchards. Forestry Chronicle 70:745-761.

Desprez-Loustau, M.-L. 2009. Alien fungi of Europe. Pages 1529 in J. A. Drake, editor. DAISIE handbook of alien species in Europe. Springer International Publishing, Dordrecht, Netherlands.

Dutech, C., B. Barrès, J. Bridier, C. Robin, M. G. Milgroom, and V. Ravignè. 2012. The chestnut blight fungus world tour: successive introduction events from diverse origins in an invasive plant fungal pathogen. Molecular Ecology 21:39313946.

Edgar, R. C. 2010. Search and clustering orders of magnitude faster than BLAST. Bioinformatics 26:2460-2461.

Edgar, R. C. 2013. UPARSE: highly accurate OTU sequences from microbial amplicon reads. Nature Methods 10:996-998.

Edgar, R. C. 2016. UNOISE2: improved error-correction for Illumina $16 \mathrm{~S}$ and ITS amplicon sequencing. bioRxiv. http:// dx.doi.org/10.1101/081257

Edgar, R. C., and H. Flyvbjerg. 2015. Error filtering, pair assembly and error correction for next-generation sequencing reads. Bioinformatics 31:3476-3482.

Elfar, K., R. Torres, G. A. Díaz, and B. A. Latorre. 2013. Characterization of Diaporthe australafricana and Diaporthe spp. associated with stem canker of blueberry in Chile. Plant Disease 97:1042-1050.

Eschen, R., T. Holmes, D. Smith, A. Roques, A. Santini, and M. Kenis. 2014. Likelihood of establishment of tree pests and diseases based on their worldwide occurrence as determined by hierarchical cluster analysis. Forest Ecology and Management 315:103-111.

Eschen, R., A. Roques, and A. Santini. 2015. Taxonomic dissimilarity in patterns of interception and establishment of alien arthropods, nematodes and pathogens affecting woody plants in Europe. Diversity and Distributions 21:36-45.

Evira-Recuenco, M., E. Iturritxa, and R. Raposo. 2015. Impact of seed transmission on the infection and development of pitch canker disease in Pinus radiata. Forests 6:3353-3368.

Eyles, A., P. Bonello, and R. Ganley. 2010. Induced resistance to pests and pathogens in trees. New Phytologist 185:893-908.

FAO. 2016. International standards for phytosanitary measures ISPM 5-Glossary of phytosanitary terms. FAO, Rome, Italy.

Farr, D. F., and A. Y. Rossman. 2019. Fungal Databases, U.S. National Fungus Collections, ARS, USDA. https://nt.arsgrin.gov/fungaldatabases/index.cfm

Folmer, O., M. Black, W. Hoeh, R. Lutz, and R. Vrijenhoek. 1994. DNA primers for amplification of mitochondrial cytochrome c oxidase subunit I from diverse metazoan invertebrates. Molecular Marine Biology and Biotechnology 3:294-9.

Gamboa, M. A., S. Laureano, and P. Bayman. 2003. Measuring diversity of endophytic fungi in leaf fragments: Does size matter? Mycopathologia 156:41-45.

Ganley, R. J., and G. Newcombe. 2006. Fungal endophytes in seeds and needles of Pinus monticola. Mycological Research 110:318-327.

Geer, L., A. Marchler-Bauer, L. Han, J. He, S. He, L. C. W. Shi, and S. Bryant. 2010. The NCBI BioSystems database. Nucleic Acids Research 38:D492-D496.
Gilbert, G. S., and C. O. Webb. 2007. Phylogenetic signal in plant pathogen-host range. Proceedings of the National Academy of Sciences USA 104:4979-4983.

Gilbert, G. S., R. Magarey, K. Suiter, and C. O. Webb. 2012. Evolutionary tools for phytosanitary risk analysis: phylogenetic signal as a predictor of host range of plant pests and pathogens. Evolutionary Applications 5:869-878.

Giordano, L., P. Gonthier, G. Lione, and M. Garbelotto. 2019. The invasiveness of a non-native fungal forest pathogen is boosted by the presence of a congeneric native species. Forestry 92:157-166.

Griffin, R. 2012. Basic concepts in risk analysis. Pages 7-18 in C. Devorshak, editor. Plant pest risk analysis: concepts and applications. CAB International, Wallingford, UK.

Guerrero, J., and S. Pérez. 2013. First report of Diaporthe australafricana-caused stem canker and dieback in European Hazelnut (Corylus avellana L.) in Chile. Plant Disease 97:1657.

Herms, D. A., and D. G. McCullough. 2014. Emerald ash borer invasion of North America: history, biology, ecology, impacts, and management. Annual Review of Entomology 59:13-30.

Higgins, K. L., A. E. Arnold, J. Miadlikowska, S. D. Sarvate, and F. Lutzoni. 2007. Phylogenetic relationships, host affinity, and geographic structure of boreal and arctic endophytes from three major plant lineages. Molecular Phylogenetics and Evolution 42:543-555

Holmes, T. P., J. E. Aukema, B. Von Holle, A. Liebhold, and E. Sills. 2009. Economic impacts of invasive species in forests: past, present, and future. Annals of the New York Academy of Sciences 1162:18-38.

Hutchinson, G. E. 1959. Homage to Santa Rosalia or why are there so many kinds of animals? American Naturalist 93:145159.

Ishida, T. A., K. Nara, and T. Hogetsu. 2006. Host effects on ectomycorrhizal fungal communities : insight from eight host species in mixed conifer-broadleaf forests. New Phytologist $174: 430-440$

Keane, R. M., and M. J. Crawley. 2002. Exotic plant invasions and the enemy release hypothesis. Trends in Ecology and Evolution 17:164-170.

Kenis, M., W. Rabitsch, M. A. Auger-Rozenberg, and A. Roques. 2007. How can alien species inventories and interception data help us prevent insect invasions? Bulletin of Entomological Research 97:489-502.

Kenis, M., M. A. Auger-Rozenberg, A. Roques, L. Timms, C. Péré, M. J. W. Cock, J. Settele, S. Augustin, and C. LopezVaamonde. 2009. Ecological effects of invasive alien insects. Biological Invasions 11:21-45.

Kreft, H., and W. Jetz. 2007. Global patterns and determinants of vascular plant diversity. Proceedings of the National Academy of Sciences USA 104:5925-5930.

Latorre, B. A., K. Elfar, J. G. Espinoza, R. Torres, and G. A. Díaz. 2012. First Report of Diaporthe australafrican Associated with Stem Canker on Blueberry in Chile. Plant Disease 96:768.

Lenth, R. V.. 2016. Least-squares means: the $R$ package lsmeans. Journal of Statistical Software 69:1-33.

Liebhold, A. M., E. G. Brockerhoff, L. J. Garrett, J. L. Parke, and K. O. Britton. 2012. Live plant imports: the major pathway for forest insect and pathogen invasions of the US. Frontiers in Ecology and the Environment 10:135-143.

Liebhold, A. M., T. Yamana, A. Roques, S. Augustin, S. L. Chown, E. G. Brockerhoff, and P. Pyšek. 2018. Plant diversity drives global patterns of insect invasions. Scientific Reports $8: 1-5$. 
Liu, Y., and F. He. 2019. Incorporating the disease triangle framework for testing the effect of soil - borne pathogens on tree species diversity. Functional Ecology 00:1-12.

Lombaert, E., T. Guillemaud, J.-M. Cornuet, T. Malausa, B. Facon, and A. Estoup. 2010. Bridgehead effect in the worldwide invasion of the biocontrol Harlequin Ladybird. PLoS ONE 5:232.

Loo, J. 2009. Ecological impacts of non-indigenous invasive fungi as forest pathogens. Biological Invasions 11:81-96.

Martin, M. 2011. Cutadapt removes adapter sequences from high-throughput sequencing reads. EMBnet.journal 17:10-12.

Mittal, R. K., R. L. Anderson, and S. B. Mathur. 1990. Microorganisms associated with tree seeds: world checklist 1990. Information Report PI-X-96. Forestry Canada, Petawawa National Forestry Institute, Chalk River, Ontario, Canada.

Myczko, Ł., Ł. Dylewski, A. Chrzanowski, and T. H. Sparks. 2017. Acorns of invasive Northern red oak (Quercus rubra) in Europe are larval hosts for moths and beetles. Biological Invasions 19:2419-2425.

Nguyen, N. H., Z. Song, S. T. Bates, S. Branco, L. Tedersoo, J. Menke, J. S. Schilling, and P. G. Kennedy. 2016. FUNGuild: an open annotation tool for parsing fungal community datasets by ecological guild. Fungal Ecology 20:241-248.

Niemiec, S. S., G. R. Ahrens, S. Willits, and D. E. Hibbs. 1995. Hardwoods of the Pacific Northwest. Oregon State University, Forest Research Laboratory, Corvallis, Oregon, USA.

Nilsson, R. H., et al. 2019. The UNITE database for molecular identification of fungi: handling dark taxa and parallel taxonomic classifications. Nucleic Acids Research 47:259-264.

O’Brien, M. J., M. Brezzi, A. S. J. Zhang, P. A. Niklaus, K. Ma, and B. Schmid. 2017. Tree diversity drives diversity of arthropod herbivores, but successional stage mediates detritivores. Ecology and Evolution 7:8753-8760.

Orlova-Bienkowskaja, M. J. 2014. Ashes in Europe are in danger: the invasive range of Agrilus planipennis in European Russia is expanding. Biological Invasions 16:1345-1349.

R Core Team. 2018. R: A language and environment for statistical computing. R Foundation for Statistical Computing, Vienna, Austria.

Rappaport, N. G., and A. Roques. 1991. Resource use and clonal differences in attack rate by Megastigmus spermotrophus Wachtl colonizing Douglas fir (Pseudotsuga menziesii [Mirb.] Franco) cones from Interior France. Canadian Entomologist 123:1219-1228

Ratnasingham, S., and P. D. N. Hebert. 2007. BOLD: the Barcode of Life Data System (http://www.barcodinglife.org). Molecular Ecology Notes 7:355-364.

Rius, M., and J. A. Darling. 2014. How important is intraspecific genetic admixture to the success of colonising populations? Trends in Ecology and Evolution 29:233-242.

Rodriguez, R. J., J. F. J. White, A. E. Arnold, and R. S. Redman. 2009. Fungal endophytes: diversity and functional roles. New Phytologist 182:314-330.

Roques, A.. 2010. Taxonomy, time and geographic patterns. Chapter 2. BIORISK-Biodiversity and Ecosystem Risk Assessment 4:11-26.

Roques, A., and M. Skrzypczyńska. 1987. Megastigmus strobilobius Ratzeburg, 1848 (Hym., Torymidae): its morphology, life history and economic significance. Journal of Applied Entomology 104:484-495.

Roques, A., and M. Skrzypczyńska. 2003. Seed-infesting chalcids of the genus Megastigmus Dalman, 1820 (Hymenoptera: Torymidae) native and introduced to the West Palearctic region: taxonomy, host specificity and distribution. Journal of Natural History 37:127-238.

Roques, A., J. H. Sun, M. A. Auger-Rozenberg, and O. Hua. 2003. Potential invasion of China by exotic insect pests associated with tree seeds. Biodiversity and Conservation 12:2195-2210.

Rouget, M., M. P. Robertson, J. R. U. Wilson, C. Hui, F. Essl, J. L. Renteria, and D. M. Richardson. 2016. Invasion debt quantifying future biological invasions. Diversity and Distributions 22:445-456.

Santini, A., et al. 2013. Biogeographical patterns and determinants of invasion by forest pathogens in Europe. New Phytologist 197:238-250.

Schena, L., F. Nigro, A. Ippolito, and D. Gallitelli. 2004. Realtime quantitative PCR: a new technology to detect and study phytopathogenic and antagonistic fungi. European Journal of Plant Pathology 110:893-908.

Schloss, P. D., et al. 2009. Introducing mothur: open-source, platform-independent, community-supported software for describing and comparing microbial communities. Applied and Environmental Microbiology 75:7537-7541.

Schneider, C. A., W. S. Rasband, and K. W. Eliceiri. 2012. NIH Image to ImageJ: 25 years of image analysis. Nature Methods 9:671-675.

Shackleton, R. T., R. Biggs, D. M. Richardson, and B. M. H. Larson. 2018. Social-ecological drivers and impacts of invasion-related regime shifts: consequences for ecosystem services and human wellbeing. Environmental Science and Policy 89:300-314.

Skrzypczyńska, M. 2015. The qualitative estimation of insects inhabiting European larch Larix decidua Mill. cones originating from the Forest District Myślenice (the Kraków Forest Region). Acta Agraria et Silvestria Series Silvestris 53:61-70.

Slippers, B., and M. J. Wingfield. 2007. Botryosphaeriaceae as endophytes and latent pathogens of woody plants: diversity, ecology and impact. Fungal Biology Reviews 21:90-106.

Storer, A. J., T. R. Gordon, and S. L. Clark. 1998. Association of the pitch canker fungus, Fusarium subglutinans f.sp. pini, with Monterey pine seeds and seedlings in California. Plant Pathology 47:649-656.

Sutherland, J. R., W. Lock, and S. H. Farris. 1981. Sirococcus blight: a seed-borne disease of container-grown spruce seedlings in Coastal British Columbia forest nurseries. Canadian Journal of Botany 59:559-562.

Taylor, D. L., W. A. Walters, N. J. Lennon, J. Bochicchio, A. Krohn, J. G. Caporaso, and T. Pennanen. 2016. Accurate estimation of fungal diversity and abundance through improved lineage-specific primers optimized for Illumina Amplicon sequencing. Applied and Environmental Microbiology 82:7217-7226.

Tedersoo, L., et al. 2014. Global diversity and geography of soil fungi. Science 346:6213.

Tedersoo, L., R. Drenkhan, S. Anslan, C. Morales-Rodriguez, and M. Cleary. 2019. High-throughput identification and diagnostics of pathogens and pests: overview and practical recommendations. Molecular Ecology Resources 19:47-76.

Turgeon, J. J., A. Roques, and P. De Groot. 1994. Insect fauna of coniferous seed cones: diversity, host plant interactions, impact and management. Annual Review of Entomology 39:179-212.

Turgeon, J., A. Tayeh, B. Facon, E. Lombaert, P. De Clercq, N. Berkvens, J. G. Lundgren, and A. Estoup. 2011. Experimental evidence for the phenotypic impact of admixture between wild and biocontrol Asian ladybird (Harmonia axyridis) involved in the European invasion. Journal of Evolutionary Biology 24:1044-1052.

Úrbez-Torres, J. R., F. Peduto, and W. D. Gubler. 2010. First report of grapevine cankers caused by Lasiodiplodia crassispora and Neofusicoccum mediterraneum in California. Plant Disease 94:785. 
van Niekerk, J. M., W. Bester, F. Halleen, P. W. Crous, and P. H. Fourie. 2010. First Report of Lasiodiplodia crassispora as a Pathogen of Grapevine Trunks in South Africa. Plant Disease 94:1063-1063.

Venette, R. C., R. D. Moon, and W. D. Hutchison. 2002. Strategies and statistics of sampling for rare individuals. Annual Review of Entomology 47:143-174.

Vettraino, A. M., R. Potting, and R. Raposo. 2018. EU legislation on forest plant health: an overview with a focus on Fusarium circinatum. Forests 9:1-18.

Vincent, J. B., G. D. Weiblen, and G. May. 2016. Host associations and beta diversity of fungal endophyte communities in New Guinea rainforest trees. Molecular Ecology 25:825-841.

Wang, Q., G. M. Garrity, J. M. Tiedje, and J. R. Cole. 2007. Naïve Bayesian classifier for rapid assignment of rRNA sequences into the new bacterial taxonomy. Applied and Environmental Microbiology 73:5261-5267.

Wang, Y., U. Naumann, S. T. Wright, and D. I. Warton. 2012. mvabund - an R package for model-based analysis of multivariate abundance data. Methods in Ecology and Evolution 3:471-474.

Warton, D. I., S. T. Wright, and Y. Wang. 2012. Distance-based multivariate analyses confound location and dispersion effects. Methods in Ecology and Evolution 3:89-101.

Zalamea, P.-C., J. W. Dalling, C. Sarmiento, A. E. Arnold, C. Delevich, M. A. Berhhow, A. Ndobegang, S. Gripenberg, and A. S. Davis. 2018. Dormancy-defense syndromes and tradeoffs between physical and chemical defenses in seeds of pioneer species. Ecology 99:1988-1998.

Zhou, L., and Y. Dai. 2011. Recognizing ecological patterns of wood-decaying polypores on gymnosperm and angiosperm trees in northeast China. Fungal Ecology 5:230-235.

\section{SUPPORTING INFORMATION}

Additional supporting information may be found online at: http://onlinelibrary.wiley.com/doi/10.1002/eap.1971/full

\section{Data Availability}

Data are available from the Dryad Digital Repository at https://doi.org/10.5061/dryad.nr51124. Raw HTS sequences have been deposited in the Sequence Read Archive under accession number PRJNA550270. Assembled ITS and CO1 sequences obtained from fungal cultures and insects have been deposited in GenBank under accession numbers MN105153-MN105593 and MN122012-MN122067, respectively. 